Delft University of Technology

\title{
Common misunderstandings in life cycle costing analyses and how to avoid them
}

van den Boomen, Martine; Schoenmaker, Rob; Verlaan, Jules; Wolfert, Rogier

DOI

10.1201/9781315375175-251

Publication date

2017

Document Version

Accepted author manuscript

Published in

Life-Cycle of Engineering Systems: Emphasis on Sustainable Civil Infrastructure

\section{Citation (APA)}

van den Boomen, M., Schoenmaker, R., Verlaan, J., \& Wolfert, R. (2017). Common misunderstandings in life cycle costing analyses and how to avoid them. In J. Bakker, D. M. Frangopol, \& K. van Breugel (Eds.), Life-Cycle of Engineering Systems: Emphasis on Sustainable Civil Infrastructure: Proceedings of the 5th International Symposium on Life-Cycle Engineering, Delft, Netherlands (pp. 1729-1735). (Life-Cycle of Civil Engineering Systems). Taylor and Francis. https://doi.org/10.1201/9781315375175-251

Important note

To cite this publication, please use the final published version (if applicable).

Please check the document version above.

\footnotetext{
Copyright

Other than for strictly personal use, it is not permitted to download, forward or distribute the text or part of it, without the consent of the author(s) and/or copyright holder(s), unless the work is under an open content license such as Creative Commons.

Takedown policy

Please contact us and provide details if you believe this document breaches copyrights.

We will remove access to the work immediately and investigate your claim.
} 


\title{
Common misunderstandings in life cycle costing analyses and how to avoid them
}

\author{
M. van den Boomen, R. Schoenmaker, J.G. Verlaan \& A.R.M. Wolfert \\ Civil Engineering and Geosciences, Delft University of Technology, Delft, The Netherlands
}

\begin{abstract}
LCC analyses (LCCA) and discounting calculations are applied by public sector organizations in the Netherlands. Still numerous misunderstandings can be recognized. An overview is given of some common misunderstandings found in Life Cycle Costing Analyses. Issues relating to public assets are: the absence of residual value, long life cycles, high investment costs, long operation and maintenance expenditures and a low discount rate. All these issues make a careful estimation of life cycles and input parameters more important than most governments and local authorities realize. Six suggestions to improve LCC analyses of public assets are given.
\end{abstract}

\section{INTRODUCTION}

Life Cycle Costing (LCC) is the process of economic analysis to assess the life cycle cost of a product over its life cycle or a portion thereof ((EN 60300-3$3: 2004$, p. 7). The purpose of life cycle costing is to support decisions on the acquisition, exploitation, rehabilitation and disposal of assets. Some common objectives of LCC are (ISO 55000:2014, p. 8):

- identification of major cost drivers;

- evaluation of the economic viability of investments;

- comparison of alternatives;

- long-term financial planning.

LCC is a vital instrument for realizing value from assets. Realization of value normally involves a balancing of costs, risks, opportunities and performance benefits (ISO 55000:2014, p. 14). Life cycle costs are the third cornerstone in the widely used asset management triangle for obtaining a healthy and long-term balance between the assets' performances, risks and costs.

In almost all books on maintenance management and asset management at least some attention is given to LCC or LCC analyses. Recent examples are Campbell, Jardine, and McGlynn (2011, ch. 12); Crespo Marquez (2007, ch. 7); Hastings (2015, ch. 8); NAMS Group International (2011, ch. 3).

However, LCC is still an area of expertise that organizations seem to struggle with. Korpi and AlaRisku (2008) conducted a systematic analysis on ac- tual implementations of LCC methods. They found 55 or around $25 \%$ of their case studies to be suitable for in depth review. First, their general observation was that "LCC case studies do not have a strong tradition in any scientific journal." Second, they observed that the "LCC methods were overall fairly unsatisfactory, in terms of all of the analyzed aspects of the cases (life cycle phases considered, information sources used, cost estimation methods used, and the deterministic nature of analyses)."

Hastings (2015, p. 93) states: "The hardest part of financial analysis is not the calculations, but deciding what factors should be taken into account and estimating the cost, revenues and risks."

In this research the findings of a practical evaluation on 10 public sector life cycle costing analyses in the Netherlands are presented. These findings are in line with what is said by Hastings (2015) and Korpi and Ala-Risku (2008). Focus is put on the comparison between mutually exclusive (cost) alternatives and replacement decisions. Attention will be given to differences between public sector assets and private sector assets and the consequences for LCC analyses. Solutions will be provided for some frequently encountered mistakes.

Public sector assets are often characterized by high investment costs, long service lives, long-term operation and maintenance expenditures, no salvage values at disposal and low discount rates. Significant amounts of money, in the order of magnitude of tons to millions of Euro's, are involved in public LCC 
analyses. Wrong calculations and wrong input will result in wrong decisions as the following two examples illustrate.

The economic replacement of a sewer main was originally calculated at 77 years, and recalculated correctly at 116 years, given a certain increasing failure rate, repair cost and discount rate. This early replacement due to wrong calculation methods would have cost the municipality involved an unnecessary $k € 30$ on an initial investment of $k € 100$ per kilometer of sewer main, including street works. So good calculations do matter. Of course financial aspects are not the only reason for replacement decisions. However, financial calculations will make the price of other decision criteria explicit.

A second example concerns a large monumental pumping station which was put on schedule for replacement due to extraordinary operation and maintenance costs compared to a modern electrified and automated pumping station. After performing a LCC analysis that accounted for the time value of money, this pumping station was taken from the replacement schedule for another 10 years of service, saving the asset owner nearly $\mathrm{k} € 300$ and additionally maintaining three specialized maintenance jobs.

In section 3 an overview is given of some common misunderstandings found in Life Cycle Costing analyses. The most concerning mistake is rooted in the inability of organizations to deal with the comparison of life cycle cost of assets with different service lives and no residual value. Before dealing with this issue, first four other common mistakes will be presented.

\section{METHODS AND MATERIALS}

All cases were found during recent asset management advisory work. References to specific organizations are avoided in order to protect the privacy of these organizations. However, all examples discussed are real and case information can be provided upon request, except from the material that is under a confidentially agreement. A total of 10 cases was analyzed, representing work of governmental organizations, water boards, water utilities, municipalities and supporting consulting agencies.

The purpose is to raise awareness, to stress the importance for developing competences, skills and attitude towards LCC analyses and to provide some guidelines to improve LCC calculations.

\section{RESULTS}

The most frequently found misunderstandings in LCC analyses are summarized below.

\subsection{Failure to Recognize the Contribution of the Time Value of Money}

Some organizations just ignore the time value of money and do not discount the cash flows that occur over time. Cash flows that occur in different years are simply added up. The main argument used is: "This approach is understood by colleagues and decision makers". This is an important and understandable argument. However, it does not justify ignoring the time value of money. The time value of money is just as real as the force of gravity. The time value of money reflects the mechanism that most value is obtained with early revenues and late expenses. Ignoring the time value of money could result in a wrong valuation of cash flows in time and successively wrong decisions.

The time value of money is even more of importance for public sector infrastructure as these assets are characterized by long service lives, large investments, major overhaul expenses and often significant operation and maintenance expenses. An oversimplified calculation is made to demonstrate the contribution of the time value of money (see Table 1). Two alternatives are presented with each investment costs, yearly operation and maintenance (O\&M) expenses during a life cycle of 80 years and no salvage values. Revenues of both assets are equal and left out of the calculation, as these will not influence the economic comparison. In the first calculation the time value of money is ignored by using a discount rate of $0 \%$ (no discounting). In the second calculation the discount rate is set at $4 \%$. Neglecting the time value of money would result in a preference for asset 2, while accounting for the time value of money would result in a preference for asset 1 .

Table 1. The impact of the time value of money

\begin{tabular}{lcccc}
\hline & Asset 1 & Asset 2 & Asset 1 & Asset 2 \\
\hline & $\begin{array}{c}\text { Ignoring the time value } \\
\text { of money }\end{array}$ & \multicolumn{2}{c}{$\begin{array}{c}\text { Accounting for the } \\
\text { time value of money }\end{array}$} \\
\cline { 2 - 5 } Investment & $1,000,000$ & $2,000,000$ & $1,000,000$ & $2,000,000$ \\
O\&M/year & 50,000 & 30,000 & 50,000 & 30,000 \\
Disc. rate & $0 \%$ & $0 \%$ & $4 \%$ & $4 \%$ \\
Asset life & 80 years & 80 years & 80 years & 80 years \\
\hline Present & $5,000,000$ & $4,400,000$ & $2,195,770$ & $2,717,462$ \\
Value & & & & \\
\hline
\end{tabular}

Guideline 1: Public sector organizations cannot ignore the time value of money when making life cycle decisions for assets with high investments, long service lives and significant operation and maintenance expenses. The time value of money is incorporated by discounting cash flows properly us- 
ing the Net Present Value (NPV) formula 1 (Brealey, Myers, \& Allen, 2011, p. 25; Fuller \& Petersen, 1996, p. 3-2; Hastings, 2015, p. 96; Prassas \& Roess, 2012, p. 11).

$$
N P V(i, N)=\sum_{t=0}^{N} \frac{C_{t}}{(1+i)^{t}}
$$

with:

$$
\begin{aligned}
& \text { NPV : Net Present Value [currency] } \\
& \mathrm{C}_{\mathrm{t}} \text { : Cash flow (in and out) at time } \mathrm{t} \\
& \text { [currency] } \\
& \text { i : Interest or discount rate per unit of time } \\
& \text { [-] } \\
& \mathrm{t} \text { : Unit of time, for example [year] } \\
& \mathrm{N} \quad \text { : Total number of units of time [-] }
\end{aligned}
$$

\subsection{Misunderstanding of the Cash Flows to be Used.}

"Fundamental to the concept of life cycle costing is a basic understanding of a product life cycle and the activities that are performed during these phases" (EN 60300-3-3:2004, p. 8).

Most cases reviewed did not comply with the definition of cash flows to be used in LCC analyses and net present value calculations. Cash flow is defined as real expected revenues and expenses. These are the revenues and expenses that can be directly attributed to the installment, operation, maintenance and disposal of assets. Common mistakes made in LCC calculations are:

- inclusion of (historic) depreciation;

- inclusion of long-term interest expenses;

- inclusion of sunk costs;

- inclusion of indirect risk costs.

Depreciation is an accounting cost, not a real expenditure. Depreciation follows from the application of national tax laws. It is mentioned on the profit and loss account in the annual report of an organization. Depreciation is not actual cash. In life cycle costing analyses with the purpose to compare mutually exclusive alternatives, depreciation should be left out of the cash flows. Instead, the investment is taken as a whole in the year(s) when this investment occurs.

There is a persistent conviction that asset replacement is justified when an asset is fully economically depreciated. Or vice versa, that an assets should not be replaced because it is not yet fully depreciated. From a life cycle costing perspective, this conviction is wrong. Even when an asset is not yet fully depreciated, it can be cheaper to replace it with a better alternative. Again, depreciation is not a cash flow. However, from a finance and accounting point of view, an accelerated depreciation could affect the yearly profit and loss account in a negative way. It is of importance to understand that LCC used for finance and accounting serves a different purpose than LCC for selecting investments or the comparison of alternatives.

Long-term interest expenses are a cash flow, real cash to be paid. However long-term interest expenses are excluded from LCC analyses for the simple reason that discounting of cash flows according to formula 1 already accounts for long-term interest payments. Inclusion of interest payments in cash flows and discounting these is not correct.

Sunk costs are expenses made in the past. These cash flows are gone and cannot influence future LCC decisions.

Indirect risk costs should be treated with care. One case dealt with cash flows that included a huge amount of yearly risk expenses, justifying immediate investments. The inclusion of risk expenses in cash flows is appropriate as long as the risk expenses are realistic and expected real cash to be paid. For example: an asset with a probability of failure and expenses when a failure occurs. In this case however, the risk expenses were extremely high $(€ 500,000$ per year), not well motivated and suggesting the inclusion of indirect risks like reputation damage. Be careful in doing so. Remember that cash flows represent real cash. When (in)direct risk expenses largely outnumber the real expected expenses a strange basis of economic comparison between different alternatives occurs. Better is to separate the economic LCC calculation from the quantification of indirect risks and present them individually. A decision maker can choose more objectively the most economic alternative, knowing for example that the cost for unwanted indirect effects may be high.

Guideline 2: Only future operational cash flows (expected real cash) are used in LCC analyses and NPV calculations (EN 60300-3-3:2004, p. 23-25; Fuller \& Petersen, 1996, ch. 4; Park, 2011, ch. 8).

Operational cash flows are summarized by:

1. Preliminary research and design:

- concept and definition;

- design and development.

2. Acquisition cash flows, such as:

- Investment including transport and installation;

- Sales of old installation, salvage value, taxes on revenues; 
- Demolition, cleaning up;

- Stock items, warehouse, liquid capital, software.

3. Ownership cash flows, such as:

- Sales and taxes on profit;

- Salaries;

- Operation and Maintenance;

- Consequential losses;

- Materials and consumables.

4. Disposal cash flows, such as:

- Demolition / Cleaning up;

- Salvage values and taxes on revenues.

Most (semi-)public sector organizations are exempted from taxes on profits and value added taxes.

\subsection{Misinterpretation of Discount Rates}

One case provided a misinterpretation of the discount rate. Here the discount rate was interpreted as a return on investment and set to zero with the remark that the public organization did not want to make a profit on the investment. A discount rate of zero means no discounting at all and ignores the time value of money. In other cases discount rates used for similar public projects showed a variation between $0 \%$ and $5 \%$ and were often not motivated.

A discount rate is used to determine the present value of future cash flows. Private sector is aimed at maximizing the wealth of private organizations, while public sector is aimed at maximizing social wealth. This mechanism is reflected in the discount rate. There are different methods to estimate the discount rate and they all have their advantages and disadvantages. One of the approaches is that the discount rate should at least cover the long-term cost of capital of an organization, including an optional risk markup.

"The cost of capital determines how an organization can raise money, through issuing stocks, bonds, borrowing or a mix of the two. Therefore this is normally considered as the rate of return that an organization would receive if it invested its money someplace else with a similar risk" (Park, 2011, p.251).

The long-term cost of capital can be estimated by calculating the organization's weighted average cost of capital (WACC) from the balance sheet, provided that the balance sheet reflects market values. The WACC approach is a common practice in the private sector but not necessarily appropriate for the public sector.

In the Netherlands, social discount rates (inflation free and including a risk markup) for public costbenefit analyses have recently been thoroughly investigated by the Werkgroep discontovoet (2015). The workgroup has used various viewpoints like the Ramsey Rule, the WACC method and the Capital Asset Pricing Model. Social discount rates for public sector projects in the Netherlands are presently recommended in a range between $3 \%$ to $5 \%$, depending on the nature and risk of the project. For public infrastructure projects the discount rate is recommended at 4,5\% (Werkgroep discontovoet, 2015, p. 16). However, depending on the individual risk of a project (cash flow in and out), deviations are possible.

Guideline 3: The Werkgroep discontovoet (2015) offers a weighted advise for social discount rates between $3 \%$ and $5 \%$ for a range of public policy areas.

Private sector or public-private sector can estimate discount rates based on the long-term weighted average cost of capital (WACC), provided that the balance sheet reflects market values, and including a risk markup, (Park, 2011, p. 250; Prassas \& Roess, 2012, p. 64).

$$
W A C C=\frac{E}{E+D} \cdot R_{E}+\frac{D}{E+D} \cdot R_{D}(1-T)
$$

with:

$\begin{array}{lll}\text { WACC } & : \text { Weighted Average Cost of Capital [-] } \\ \mathrm{E} & : \text { Market value of equity [currency] } \\ \mathrm{R}_{\mathrm{E}} & : \text { Cost of Equity plus risk markup [-] } \\ \mathrm{D} & : \text { Market value of long-term debt } \\ & & \text { [currency] } \\ \mathrm{R}_{\mathrm{D}} & : \text { Cost of long-term debt [-] } \\ \mathrm{T} & : \text { Corporate tax rate [-] }\end{array}$

\subsection{Misunderstanding of Inflationary Effects}

In several cases price increases were incorporated in cash flow developments. When dealing with price increases, one has to be careful and state explicitly whether the price increases include general inflation, differential inflation, both or none. The latter is applicable when price increases are caused by more consumption or increasing repairs.

General inflation (Consumer Price Index) is applicable to all goods and services. In most economies, everything gets equally more expensive in time. Differential inflation is an inflationary effect on top of the general inflation. It applies for specific segments of the economy, for example raw materi- 
als, industrial goods, special products and special services. Together, general inflation and differential inflation are called the total inflation or total price escalation rate. The total inflation is defined as the sum of the general inflation, the differential inflation and the multiplication of both.

Why is this important? When general inflation is incorporated in cash flows, general inflation should also be incorporated in the discount rate.

In that case one should discount with a nominal interest rate or nominal discount rate, comparable to a market interest rate. The nominal discount rate is equal to the sum of the real (inflation free) discount rate, the general inflation and the multiplication of both. When general inflation is left out of the cash flows, general inflation should also be left out of the discount rate. In that case one should use the real discount rate or inflation free discount rate, comparable with a real interest rate. Following these rules will yield the same results. For practical reasons general inflation is often left out of the cash flows and the cash flows are discounted with an inflation free discount rate. In doing so, one should remember, when applicable, to incorporate differential inflation only, in the cash flows.

Only few of the cases that were investigated handled inflationary effects correctly. Most were wrong, or inflationary effects were ignored for reasons of simplicity. Ignoring existing inflationary effects will yield wrong results as well.

Guideline 4: Always state how more consumption or more repairs, general inflation and differential inflation contribute to price increases and cash flow forecasts. When general inflation is left out of the cash flow forecast, cash flows should be discounted with a real discount rate (free from general inflation). When general inflation is included in the cash flow forecast, the cash flows should be discounted at the nominal discount rate (including general inflation) (Fuller \& Petersen, 1996, p. 3-11; Park, 2011, ch. 11).

\subsection{Using a Wrong Calculation Period}

In the economic comparison of public sector assets, asset life cycles are often adjusted to analysis periods preferred by governments without a proper truncation of cash flows at the end of this period. This proper truncation is difficult because public sector assets mostly lack residual value.

The argument used for completely cutting off cash flows at the end of an analysis period is the lack of influence and perceived uncertainty beyond a certain time horizon while forgetting that zero cash flows are often more unlikely than any other estimation. For example, time horizons of 15 years were seen in NPV calculations dealing with assets that had life cycles of over 50 years. 35 years of life cycle cash flows were simply ignored. leading to an unfair comparison between different alternatives.

A second observation is a strong emphasis of governments on standardization of analysis periods and asset life cycles. Again, this is done for the perceived ease of comparison and simultaneously because the net present values are used for budget forecasts.

The major mistake in these approaches is the confusion of the use of NPV-calculations for selecting the most economic alternative and NPV-calculations for estimating future budgets and price developments. These are two different purposes and should be treated differently. Correct would be to first use an appropriate time horizon and cash flows for selecting the most economic alternative and second to use an (other) appropriate time horizon and costs for the budgeting and financing question.

What would be an appropriate time horizon for comparison between different alternatives knowing that in practice most asset lives are unequal? Some common practices to deal with unequal asset lives are summarized below (Fuller \& Petersen, 1996, p. 2-8; Park, 2011, p. 264).

The first is to use an infinite time horizon or calculation period. This is a common approach for capital infrastructure assets with long service lives. Choosing a time span of say 200 years for public infrastructure assets can also approximate infinity. These 200 years are based on the order of magnitude of investments and operation and maintenance expenses involved in combination with low discount rates that apply for many public sector assets.

A second approach is choosing a finite time horizon. When an asset's life is longer than this period, one should use a proper truncation at the end of this time horizon. A proper truncation should be realistic and could be a salvage value or residual value. Here a difficulty with public infrastructure assets arises. Public infrastructure assets often do not have a salvage value like ships, airplanes, buildings trucks and cars. Taking book value as an estimation for salvage value, which was seen in a couple of cases, is not correct. Book value is not real cash. A bridge, for example, cannot be sold after 20 years. It is also not realistic to assume demolition of an asset before its technical, economical or functional life. A better estimation would be assuming that the cash flow at the end of the time horizon will continue each year to the end of the asset life. Discounting this stream of cash flows beyond the time horizon will yield an estimation for the residual value at the end of the time horizon. This approach was seen in one case. How- 
ever, one should realize that this approach does not differ (much) from using the individual asset lives as time horizons for present value calculations. This approach suggests that a present value comparison between equal lives alternatives is made, which is actually not true as a present value comparison is made between unequal lives, resulting in an unfair comparison.

A third approach is called the least common multiple (LCCM) approach. The time horizon or calculation period is based on the least common multiple of the asset lives. For example, given three mutually exclusive alternatives with respective asset lives of 30,50 and 60 years, the least common multiple is 300 years. One should take 10 reinvestments of alternative 1, 6 reinvestments of alternative 2 and 5 reinvestments of alternative 3 . This type of approach was seen in a number of cases and this is correct but a bit cumbersome. However, Excel can deal with this simply.

A fourth approach is the Equivalent Annual Cost (EAC) approach. This approach was seen in none of the cases. The EAC is an equal annual series of cost over the asset life. First the cash flows during an asset life are used to calculate the present value. Second, the present value is transformed into an annual equivalent series of cost according to formula 3 , just for the purpose of comparison. Based on equivalent annual cost, mutually exclusive alternatives with different asset lives can be compared to each other.

Guideline 5: Separate the question of comparing mutually exclusive alternatives from the question of financing and budgeting. Choose an appropriate time horizon for comparing and selecting between alternatives. For public infrastructure with long asset lives and no residual value, one could use one of the following approaches:

- use an infinite time horizon or an approximation of infinity and compare based on present value;

- use the least common multiple time horizon and compare based on present value;

- use the individual (unequal) assets lives as time horizons and compare based on equivalent annual cost (EAC).

The Equivalent Annual Cost can easily be derived from the NPV-formula 1 and is given by (Brealey et al., 2011; Hastings, 2015, p. 141; Park, 2011, p. 267; Prassas \& Roess, 2012, p. 19):

$$
E A C=\frac{i \cdot(1+i)^{n}}{(1+i)^{n}-1} \cdot N P V
$$

with:
EAC : Equivalent Annual Cost [currency /unit of time]

i : Interest or discount rate per unit of time [-]

$\mathrm{n}$ : Units of time [number of units of time]

NPV : Net Present Value [currency]

\subsection{Sensitivity and Scenario Analyses are Lacking}

In all cases sensitivity and scenario analyses were missing. In LCC analyses these are really important to support final decision making. Especially for capital infrastructure with long service lives and a low discount rates. The future is by definition uncertain. This holds for cash flow estimations, long-term discount rates and asset lives. Final results of calculations should always be presented with a margin and likelihood of occurrence. Some available and practical methodologies for including uncertainties are:

- perform sensitivity analyses on input variables to find those that strongly influence outcomes;

- work with worst, average and best case scenarios and assign probabilities to these outcomes;

- work with probability distributions on the heights of cash flows;

- work with probability distributions on the time of occurrence of cash flows.

Guideline 6: Perform sensitivity and scenario analyses on the LCC analyses for the input parameters: cash flows, discount rate and asset lives and present results in a range with a likelihood of occurrence.

\section{DISCUSSION}

Ten present value calculations from public sector organizations and supporting consultancies were analyzed. Based on recalculations other asset investment or replacement decisions would have been advised in the majority of the cases. The majority of the calculations performed by the organizations show lack of a thorough understanding of both input parameters and LCC calculation methods. In some cases, methods and starting points were presented as facts and shared explicitly. In other cases these assumptions were left implicit.

In addition a growing number of NPV calculation tools in the form of spreadsheets and software is seen. The correctness of the calculation methods of some of these tools is questionable. For example, software is available that includes book value, interests and depreciation costs in NPV calculations for comparing mutually exclusive alternatives. Another algorithm was seen in which 'discounting' was modeled by the sum of income, depreciation costs, inter- 
est expenses, operation and maintenance expenses. Most tools that were seen could not deal with the comparison of assets or projects with different lives. However, most concern lies with policy makers using these tools without understanding the basics of the LCC methodology. Even the best software does not protect a user against incorrect inputs and incorrect interpretation of results. Additionally, a user should be able to recalculate the results on a higher level to check the order of magnitude of the outcomes.

At present sufficient knowledge on finance, accounting and LCC calculations seems to be absent with policy makers performing and sharing these type of calculations. More awareness on this subject and developing competences, skills and attitude towards LCC analyses is needed.

The danger of six suggestions for LCC analyses is that an impression may be given that LCC analyses are easily mastered. LCC is not rocket science but nevertheless a professional area of expertise. A solid comprehension of accounting and finance is required, followed by serious study and practice on LCC methodology. Looking at LCC from a higher perspective, a proper LCC analysis needs:

1. A well defined LCC question;

2. A well defined LCC calculation model appropriate for this question;

3. A good understanding of input parameters and development in time;

4. A good interpretation of results including a sensitivity, scenario and probability analyses.

\section{REFERENCES}

Brealey, R. E., Myers, S. C., \& Allen, F. (2011). Principles of Corporate Finance. New York: McGraw-Hill/Irwin.

Campbell, J. D., Jardine, A. K. S., \& McGlynn, J. (2011). Asset management excellence : optimizing equipment life-cycle decisions. Boca Raton, FL: CRC Press.

Crespo Marquez, A. (2007). The Maintenance Management Framework : models and methods for complex systems maintenance. London: Springer.

EN 60300-3-3:2004. Dependability management - Part 3-3: Application guide - Life cycle costing

Brussels: European Committee for Electrotechnical Standardization.

Fuller, S. K., \& Petersen, S. R. (1996). Life Cycle Costing Manual for the Federal Energy Management Program. NITS Handbook 135. Washington: Department of Commerce.

Hastings, N. A. J. (2015). Physical asset management. London ; New York: Springer.

ISO 55000:2014. Asset management - Overview, principles and terminology. Geneva, Switserland: ISO.

Korpi, E., \& Ala-Risku, T. (2008). Life cycle costing: a review of published case studies. Managerial Auditing Journal, 23(3), 240 - 261.
NAMS Group International. (2011). Infrastructure Management Manual (4th Edition ed.). Thames, New Zealand: National Asset Management Steering Group.

Park, C. S. (2011). Contemporary Engineering Economics. (Fifth Edition ed.). New Jerssey: Pearson.

Prassas, E. S., \& Roess, R. P. (2012). Engineering Economics and Finance for Transportation Infrastructure. BerlinHeidelberg: Springer-Verlag.

Werkgroep discontovoet. (2015). Rapport werkgroep discontovoet 2015. Retrieved from http://www.tweedekamer.nl/kamerstukken/detail?id=2015D 43793 